\title{
Relationship of Facebook Use and Scholastic Performance: The Case of Filipino Senior High School Students
}

\author{
Jezreel Garzon ${ }^{1}$, Nami Kim², Cheong Hoon $\mathrm{Kim}^{3 *}$ \\ ${ }^{1}$ Doctorate Student, Addiction Science Department \\ Sahmyook University (Seoul, Korea) \\ ${ }^{2}$ Department Head, Addiction Science Department \\ Sahmyook University (Seoul, Korea) \\ ${ }^{3}$ Assistant Professor, Addiction Science Department \\ Sahmyook University (Seoul, Korea) \\ *corresponding author's email: ckim [AT] syu.ac.kr
}

\begin{abstract}
High school students in the Philippines nowadays are engaged into Facebook. It is the most commonly used social networking site in the Philippines. This research assessed the Facebook Use of 591(235 male, 356 female) randomly selected Filipino senior high school students in Southern Philippines for school year 2017. 2018. Bergen Facebook Addiction Scale determined the degree of students' Facebook Use. It was found out that 362(61.3\%) students are classified as Facebook addict and 229(38.7\%) are classified non-Facebook addict. In the comparison between students' time spent on Facebook, it was found out that the less time they spend on Facebook, the lower grades they get in school. Furthermore, the more gadgets they have at home the better scholastic performance they have. The correlation between Facebook use and Scholastic performance showed that there is no association between the two variables.
\end{abstract}

Keywords—-Facebook Addiction, senior high school, scholastic performance, Bergen Facebook addiction scale

\section{INTRODUCTION}

The presence of technology in today's world makes our lives easier and productive than any generation many years before us. The good thing in our time is that technology is not only limited in science laboratories, factories, or in space but right in our hands within the boundaries of the average person's day-to-day life. Everything from smart phones, personal laptop computers, to tablets and iPods make our lives more comfortable. We often interact with technology in some of the most mundane things of life [1]. Technology has enabled people to new levels of convenience at school, home, in the office, and nearly everywhere else. By connecting through mobile devices and through advancements from the Internet of Things, daily tasks are now easier to complete and the access to information is in real time [2].The onset of this convenience affects people's lives. In the case of students, they open several internet sites that enable them to access information of different forms and also connect with friends and share daily activities.

In the study of [3], result showed that the average time American college students use the internet is 100 minutes a day. The top reason of their internet use is to browse the World Wide Web for some information that might be useful in their daily lives. The content of sites and the purpose of students' internet vary depending on the major that they are taking in school. Another study which classified students into heavy and non-heavy internet users indicated that nonheavy users were able to establish better relationships with their school's administrative staff, good academic grades, and are more satisfied in their learning. Heavy internet users were found out to be more depressed, physically ill, lonely, and introverted [4].

Facebook can be used to communicate with people but it can also be detrimental to students' scholastic performance if the time spent on it is uncontrolled. Social networking site in today's generation is just one of the many things that enable the students to multitask. Multi-tasking may have positive or negative contribution in their lives due to the fact that they need to maintain a good performance in doing a certain task [5].

In the Philippines, more of the students' internet use time is spent browsing Facebook. This is the easiest way to access the internet the reason is that many telecommunication service providers offer a free limited data where they can browse Facebook. Some service providers also offer an unlimited Facebook use for a very low cost. Low cost in the 
sense that this service enables them to use only Facebook. In the study of [6] they stated that one of the reasons of students' use of internet is to communicate with friends.

Being adolescent, students are in the stage of life wherein they are vulnerable to the influence of different aspects in the environment. [7] stated that people who belong to this group have high levels of exploration, risk taking, novelty and sensation seeking, and social interaction and play behaviors. In addition, the ongoing neurodevelopment of adolescents is responsible for their curiosity and impulsivity. This explains why teenagers are critical to outside influences [8]. Besides, it is in this part of life that physical, mental, and emotional aspects of life are established. The habits and values developed here will be the foundation of one's future characteristics so supervision of parents is vital in this area [9].

Academic performance is also very important in a person's life for it can be bases of future endeavors. It is a finding that previous academic performance is the most significant predictor of a good university performance. High school students who performed well academically are the ones who do well in the university setting. Academic performance according to [10] is also a positive predictor of success in career, creativity, and good job performance. Constant connection and sharing of activities lead students to spend more time using Facebook. Student as they are, they have busy schedule and they have subjects in school to master and of course a grade to maintain in order to have a good standing in school. Scholastic performance is very significant in landing a good job in the future. This is the basis of companies and other institutions in hiring highly competent employees. With this, it is very important that students while still in school must accumulate high academic standing. Specifically, this research aims to identify the impact of Filipino senior high school students' Facebook use to their scholastic performance.

\section{METHODOLOGY}

\subsection{Participants}

The respondents of this study are 591(235 male, 356 female) Filipino senior high school students of 5 different senior high schools in Region 12, Southern Philippines (Fatima Senior High School, Malandag Senior High School, Alabel Integrated School, Irineo L. Santiago Senior High School, and New Society Senior High School) . They are bona fide students in the school year 2017-2018. They were randomly selected from the population of students who declared themselves as Facebook users.

\subsection{Instrument}

There is 1 instrument used in this research. The Bergen Facebook Addiction Scale (BFAS). BFAS is a self-report questionnaire. The six items are representative of the six core components proposed by [11] and [12] such as: 1) saliencethe activity dominates thinking and behavior, 2) mood modification-the activity modifies or improves mood, 3) tolerance-increasing amounts of the activity are required to achieve previous effects, 4) withdrawal-the occurrence of unpleasant feelings when the activity is discontinued or suddenly reduced, 5) conflict- the activity causes conflicts in relationships, in work/education and other activities, 6) relapse-a tendency to revert to earlier patterns of the activity after abstinence or control. BFAS's wording imitated the diagnostic criteria for pathological gambling produced by the American Psychiatric association and in the Game Addiction Scale. Each item is scored on a 5-point scale; $1=$ Very rarely, $2=$ Rarely, $3=$ Sometimes, $4=$ Often, $5=$ Very often. The total score ranges from 6 to 30 points. 16 points or more indicates Facebook Addiction [13],[14].

\subsection{Procedure}

For each school, the participants were randomly selected by the school guidance counselor based on the master list of students per class given by the classroom teachers. After obtaining the respondents, their participation in the research was explained properly and they voluntarily agreed. They convened in a room and they were given a set of questionnaire which includes demographic profile questions and the Bergen Facebook Addiction Scale. Each set of questionnaire was numbered in order to identify its owner. The respondents' General Point Average (GPA) in the previous term was secured from their class advisers to represent the scholastic performance in this research.

\subsection{Data Analysis}

This is a quantitative study and SPSS 23 was used to analyze the data. Descriptive statistics (mean, standard deviation, and percentage) were applied to organize the general characteristics of the respondents.

$\mathrm{T}$ test was used to compare the means of 1) male and female students' Facebook use and academic performance 2) younger (17y/o below) and older (18y/o and above) students' Facebook use and Academic Performance 3) students with internet connection and students without internet connection's Facebook use and academic performance 4) students who often pay in their use of Facebook and students who don't often pay the use of Facebook's Facebook use and Academic Performance. The same tool was used to identify the difference between Facebook Addicted and Non-Facebook 
Addicted Students' academic performance.

Cronbach Alpha was used to identify the validity of the questionnaires used.

Analysis of Variance (ANOVA) was used to determine the difference in the variances of students who have 1) 1 to 2 gadgets 2)3 to 4 gadgets 3) more than 5 gadgets available at home to access Facebook. ANOVA was also used in identifying the difference in the Facebook use status and scholastic performance of students who spend different lengths of time a day and a week (see table 1) using Facebook.

\section{RESULSTS}

The reliability of Bergen Facebook Addiction Scale (BFAS) based on the responses of the participants was examined and the Cronbach Alpha Coefficient value obtained was $\alpha=.771$. This indicated that the scale was acceptable to measure the students' Facebook use.

Table 1: Descriptive Analysis of the General Characteristics of Respondents

\begin{tabular}{|c|c|c|c|}
\hline Var & & $n$ & $\%$ \\
\hline \multirow{2}{*}{ Gender } & Male & 235 & 39.8 \\
\hline & Female & 356 & 60.2 \\
\hline \multirow{2}{*}{ Age } & Younger (17y/o and below) & 322 & 96.3 \\
\hline & Older(18/o and above) & 269 & 3.7 \\
\hline \multirow{2}{*}{ Internet Connection at Home } & Yes & 157 & 26.6 \\
\hline & No & 434 & 73.4 \\
\hline \multirow{2}{*}{ Often Paid use of Facebook } & Yes & 345 & 58.4 \\
\hline & No & 246 & 41.6 \\
\hline \multirow{3}{*}{$\begin{array}{r}\text { Number of gadgets available } \\
\text { to access Facebook }\end{array}$} & 1-2 gadgets & 442 & 74.8 \\
\hline & 3-4 gadgets & 116 & 19.6 \\
\hline & $>5$ gadgets & 33 & 5.6 \\
\hline \multirow{4}{*}{$\begin{array}{l}\text { Time spent using } \\
\text { Facebook in a day }\end{array}$} & $<1$ hour & 182 & 30.8 \\
\hline & 1-3 hours & 248 & 42.0 \\
\hline & 4-6 hours & 114 & 19.3 \\
\hline & $>6$ hours & 47 & 8.0 \\
\hline \multirow{4}{*}{$\begin{array}{r}\text { Time Spent using Facebook } \\
\text { in a Week }\end{array}$} & $<6$ hours & 170 & 28.8 \\
\hline & 6-8 Hours & 173 & 29.3 \\
\hline & 9-10 Hours & 106 & 17.9 \\
\hline & $>10$ hours & 142 & 24.0 \\
\hline
\end{tabular}

This study was participated by 235 male(39.8\%) and 356 female $(60.2 \%)$ senior high school from 5 different schools in region 12, Southern Philippines. The ages of the Respondents in this study fall from 16-22 years old so they were classified into 2 into groups. The younger group who are 17 years old and below are composed of 322(96.3\%) and the older group who are 18 years old and above are composed of 269(3.37\%) students.

There are 157(26.6\%) students who have their own internet connections at home and 434(73.4\%) students don't have their own internet connection at home.

426(72.1\%) students declared that they use only free Facebook and 165(27.9\%) declared that they don't use free Facebook. 345(58.4\%) declared that they often pay to use Facebook and 246(41.6\%) do not often pay in their use of Facebook.

In terms of the availability of gadgets at home that they can utilize to access Facebook, 442(74.8\%) have 1 to 2 gadgets, $116(19.6 \%)$ have 3 to 4 gadgets, 33(5.6\%) have more than 5 gadgets.

Students' time spent on Facebook a day varies. 182(30.8\%) spend less than an hour on Facebook per day, 248(42\%) students spend 1 to 3 hours, 114(19.3\%) students spend 4 to 6 hours, 47(8\%) spend more than 6 hours a day.

The respondents' time spent on Facebook a week showed that 170(28.8\%) students spend less than 6 hours, $173(29.3 \%)$ spend 6 to 8 hours, 106(17.9\%) spend 9-10 hours, 142(24\%) spend more than 10 hours. 
Table 2: The Comparison of Means of the General Characteristics of Respondents

\begin{tabular}{|c|c|c|c|c|c|c|c|}
\hline \multirow{2}{*}{\multicolumn{2}{|c|}{ Variables }} & \multicolumn{3}{|c|}{ Facebook Use } & \multicolumn{3}{|c|}{ Scholastic Performance } \\
\hline & & $\mathrm{M} \pm \mathrm{SD}$ & $t$ or $F$ & $p$ value & $\mathrm{M} \pm \mathrm{SD}$ & $\mathbf{t}$ or $F$ & $p$ value \\
\hline \multirow{2}{*}{ Gender } & Male & $16.69 \pm 4.13$ & \multirow{2}{*}{.643} & \multirow{2}{*}{.520} & $84.68 \pm 4.12$ & \multirow{2}{*}{6.31} & \multirow[b]{2}{*}{$.000 *$} \\
\hline & Female & $16.46 \pm 4.16$ & & & $86.81 \pm 3.93$ & & \\
\hline \multirow{2}{*}{ Age } & Younger (17y/o and below) & $16.58 \pm 4.18$ & \multirow[b]{2}{*}{.217} & \multirow[b]{2}{*}{.828} & $86.19 \pm 4.04$ & \multirow[b]{2}{*}{1.48} & \multirow[b]{2}{*}{.138} \\
\hline & Older (18y/o and above) & $16.51 \pm 4.12$ & & & $85.69 \pm 4.24$ & & \\
\hline \multirow{2}{*}{$\begin{array}{r}\text { Internet Connection } \\
\text { at Home }\end{array}$} & Yes & $16.91 \pm 3.86$ & \multirow{2}{*}{1.272} & \multirow{2}{*}{.204} & $85.48 \pm 4.43$ & \multirow{2}{*}{1.62} & \multirow{2}{*}{.106} \\
\hline & No & $16.42 \pm 4.25$ & & & $86.14 \pm 4.02$ & & \\
\hline \multirow{2}{*}{$\begin{array}{r}\text { Often paid use of } \\
\text { Facebook }\end{array}$} & Yes & $16.77 \pm 4.05$ & \multirow{2}{*}{1.56} & \multirow{2}{*}{.120} & $85.69 \pm 4.19$ & \multirow{2}{*}{1.37} & \multirow{2}{*}{.170} \\
\hline & No & $16.24 \pm 4.28$ & & & $86.16 \pm 4.09$ & & \\
\hline \multirow{3}{*}{$\begin{array}{r}\text { Number of gadgets } \\
\text { available to access } \\
\text { Facebook }\end{array}$} & 1-2 gadgets & $16.32 \pm 4.02$ & \multirow{3}{*}{2.724} & \multirow{3}{*}{.066} & $85.62 \pm 4.13$ & \multirow{3}{*}{6.26} & \multirow{3}{*}{$.002 *$} \\
\hline & 3-4 gadgets & $17.28 \pm 4.49$ & & & $86.90 \pm 3.80$ & & \\
\hline & $>5$ gadgets & $17.03 \pm 4.36$ & & & $87.27 \pm 4.68$ & & \\
\hline \multirow{4}{*}{$\begin{array}{l}\text { Time spent using } \\
\text { Facebook a day }\end{array}$} & $<1$ hour & $14.99+4.44$ & \multirow{4}{*}{18.21} & \multirow{4}{*}{$.000 *$} & $85.52 \pm 4.19$ & \multirow{4}{*}{3.26} & \multirow{4}{*}{$.021 *$} \\
\hline & 1-3 hours & $16.65 \pm 3.78$ & & & $85.74 \pm 4.04$ & & \\
\hline & 4-6 hours & $18.30 \pm 3.66$ & & & $86.87 \pm 4.27$ & & \\
\hline & $>6$ hours & $17.81 \pm 3.83$ & & & $86.66 \pm 3.80$ & & \\
\hline \multirow{4}{*}{$\begin{array}{l}\text { Time spent using } \\
\text { Facebook a week }\end{array}$} & $<6$ hours & $14.94 \pm 4.27$ & \multirow{4}{*}{15.129} & & $85.79 \pm 4.24$ & & \\
\hline & 6-8 hours & $16.61 \pm 3.53$ & & $\mathbf{0 0 0 *}$ & $85.25 \pm 4.14$ & & \\
\hline & $9-10$ hours & $17.83 \pm 4.02$ & & .000 & $86.27 \pm 3.87$ & 4.02 & $.008 *$ \\
\hline & $>10$ hours & $17.45 \pm 4.22$ & & & $86.81 \pm 4.07$ & & \\
\hline
\end{tabular}

Table 2 shows the comparison of means of the students' general characteristics. T-test result $(\mathrm{p}=.520>.05)$ showed that there is no significant difference between the male and female students' Facebook Use. In the scholastic performance of students, result shows that there is a significant difference between gender $(\mathrm{p}=.000<.05)$. Between the younger and older groups, findings indicate that there is no significant difference on their Facebook Use $(p=.828>.05)$ and their Scholastic Performance $(\mathrm{p}=.138>.05)$. In terms of internet connection at home, there is no significant difference between students who have internet connection and students who don't have internet connection when it comes to their Facebook Use $(p=.204>.05)$ and their Scholastic Performance $(p=.106>.05)$. In case of the students who pay to use Facebook and those who availed the Free Facebook, still there is no significant difference in their Facebook Use $(p=.120>.05)$ and Scholastic Performance $(\mathrm{p}=.170>.05)$.

Students have several ways to access Facebook based on the number of gadgets that they have at home. They are classified into 3 groups and they can fall into the ones who have 1-2 gadgets, 3-4 gadgets, and 5 or more gadgets. Among them, there is no significant difference in their Facebook Use $(p=.066>.05)$ but there is significance in their Scholastic Performance $(p=.002<05)$. The participants' time spent on Facebook per day vary. They were classified into four groups (less than 1 hour, 1-3 hours, 4-6 hours, and more than 6 hours a week). The result after the One-Way Analysis of Variance showed that there is a significant difference in their Facebook Use $(p=.000<.05)$ and Scholastic Performance $(\mathrm{p}=.021<05)$.

The total time that students spend on Facebook in a week also vary depending on their situation. They fell into 4 classifications as well (less than 6 hours, 6-8 hours, 9-10 hours, and more than 10 hours a week). After the One-Way ANOVA analysis, the findings is there are significant difference on their Facebook Use $(\mathrm{p}=.000<.05)$ and Scholastic Performance $(\mathrm{p}=.008<.05)$. 


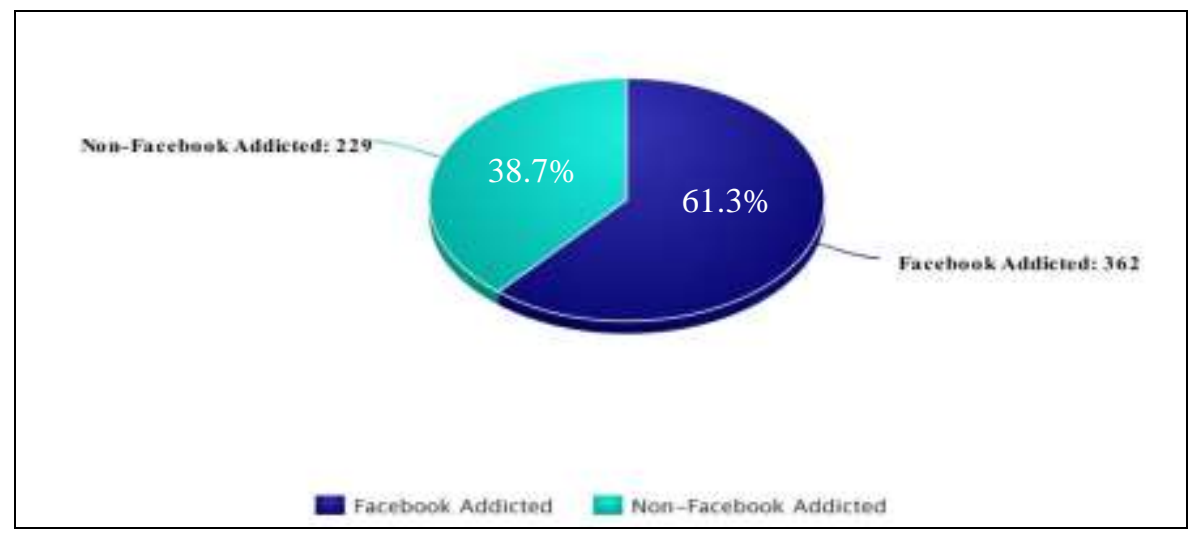

Figure 1: Percentage of Senior High School students' Facebook-use status

Figure 1 shows the Senior high school students' Facebook-use status. It indicated that there are $362(61.3 \%)$ students classified as Facebook addict, and there are 229 (38.7\%) students classified as Non-Facebook addict based on the standard of the Bergen Facebook Addiction Scale.

Table 3: Association between Facebook Use and Scholastic Performance

\begin{tabular}{lcc}
\hline & Facebook-Use & Scholastic Performance \\
\hline Facebook-Use & 1 & \\
Scholastic Performance & .080 & 1 \\
\hline
\end{tabular}

$* p<.05, * * p<.01, * * * p<.001$

The correlation analysis result $(\mathrm{p}=.080>.05)$ showed that there is no association between the students Facebook Use and Scholastic Performance.

\section{DISCUSSION}

Many of the students nowadays are engaged into several activities online. Social Networking Sites are very common around the world. Through SNS, students can communicate with people in just a few clicks.

This study aimed to assess the senior high school students' Facebook-use and its relationship to their Scholastic Performance. Findings revealed that majority of the students are addicted to Facebook and it is also true to the previous research with Turkish Students who used Facebook for several years. Students commonly use Facebook when they are at home, in the dormitory, and in the internet cafes [15]. The main motive of students' Facebook use is to maintain or establish social connections and they are not aware that their use reaches to a high level and compromises their other roles in life as a student or a member of a family [16]. A systematic review of students' use of Facebook showed that adolescents are in the point of their lives wherein they love to share whereabouts of themselves and they do it through sharing of photos, posting comments, and sharing posts [17]. [18]supports the idea that many Facebook addicted students have much free time and they often use Facebook wherever they are to kill the time.

In terms of Facebook use, there is no difference between male and female students. There are no literatures supporting that there are no differences between female and male students' Facebook use. In contrast, there are many researches saying that female users spend much time on Facebook. [19] found out that female sacrifice their sleeping time in order to use Facebook and they post more complicated photos. These actions create a standard of what a woman's body image must be.

Result showed that there is a significant difference between male and female students' academic performance. It turned out that female students have better grades than male students. One study supports this notion because in the case of Malaysian nursing students, male and female have different motivations and attitudes towards academic matters [20]. Female students are more inclined in language and art while men are into mathematics. [21] had the same claim when they found out that in a big university in Turkey, male students had better scores in entrance examinations because of their capability in taking the test but in their academic lives, female students outperform them. The content of tests is based on cognitive aspects while the measure of giving grades to students in their day to day academic lives is performance based which includes social, emotional, physical, and mental aspects. Evidence that supports the findings that female students do well in academic than boys is that female have concrete career plan in achieving higher level of education. They have plans on what career to pursue in college in the university that drives them to perform well in order to qualify to specific standards [22].

In the homes where the participants belong, the number of gadgets that they can use to access Facebook varies depending on their financial capability of having them. Data showed that there is no significant difference among students with 1 gadget, 2 gadgets, or several gadgets when it comes to Facebook use. [23] wrote that participants in her 
research declared that they use more than 1 electronic device to access the internet. The availability of several gadgets at home or in the school made it easy to access the World Wide Web and social networking sites are part of it. [24] in his article mentioned that when a person uses several electronic devices in a specific period of time, it is difficult for him to stay focused on all the activities they engaged in. With that, family relationships, household tasks, and academic matters might be affected. But in this research, result revealed that the more gadgets they have, the better grades they get in school. The article of [25] stated that students nowadays are in the generation of multi-tasking. They go to school with several social media devices that they can use to access more information online and communicate directly with teachers and classmates. These devices are also used to make their school tasks and presentations more effective and interesting. A study on language learning in Saudi Arabia showed that students with electronic gadgets are learning English language easily. A very big percentage of students who use smartphones search academic-related items in their smartphones and it can help them enrich their vocabularies and excel in this particular subject in school [26]. [27] support the findings that technology have roles in the development of children. Their access contributed to their learning potentials but they warn the parents to encourage educational use of these technologies so that it will be useful in improving academic achievement.

In the aspect of time spent on Facebook, there is a significant difference between students who spend less time and more time on Facebook. The result of the assessment showed that students who spend 4-6 hours a day on Facebook have the highest mean and are more addicted than those who spend less than 4 hours a day. Those who spend more than 6 hours a day are found to have lesser mean but still classified as addicted to Facebook. The reasons why students use Facebook are to join groups, share photographs, investigate identities, social network surfing, and status updates. Social connection and surveillance are the most common reasons why students use Facebook [28]. According [29], many American students stay connect on Social Networking Sites because they offer them various potential academic and professional opportunities. Through SNS, they can also access to large knowledge base. With these purposes, they spend more time on SNS and addiction is the consequence. A previous study on American young adults proved that Facebook is part of young adults' lives. Even if they are very busy, participants responded that they spend approximately 30 minutes using Facebook daily.

The result on the time spent on Facebook and Scholastic performance showed that the more time they spend on Facebook; the better grades they receive. It means that those students who spend much time Facebooking received good grades in school. Students who use Internet including SNS merely for entertainments have impaired academic performance for their long hours spent can lead to lack of sleep and tiredness the next day. Students who use the internet for general purpose including the search for useful information reported to have good performance academically [30].

There is no relationship between the students' Facebook use and Academic performance. [31] discovered in their previous research that there is no significant relationship between students' Facebook use and their academic performance. They did not find any relationship between the students' Facebook use and school grades. This is also true in the study of [32]. They found no significant differences between the general point average (GPA) of Facebook and Non-Facebook users.

\section{CONCLUSION \& RECOMMENDATIONS}

In conclusion, this investigation found out that Filipino senior high school students are classified as addicted to the social networking site, Facebook based on the Bergen Facebook Addiction Scale results. Students are regarded as Facebook addicts but their Facebook use does not have relationship in their Scholastic performance. It explains further that whether they are addicted or not, they can do well in the academic aspect.

Result indicated that students who spent more time using Facebook had better school grades than those who spent less time. Therefore, identifying the factors that contributed to getting better grades in the part of students who spend much time using Facebook can be a good subject of future research.

Another possible suggestion for future study is to identify the trend of students' use of gadgets because as indicated, students who have several gadgets at home to access Facebook had better scholastic performance than those who had limited.

\section{ACKNOWLEDGMENT}

The authors are expressing their gratitude to all the people behind the success of this research. This would not be possible without your sincere contributions. To the Addiction Science Department of *** University and to the personnel of the 5 schools who participated in this study, you are treasured and appreciated. 


\section{REFERENCES}

[1] Kvavik, Roberto B., "Convenience, communications, and control: How students use technology”, Educating the Net Generation, vol. 1, no. 2005, pp.7-1, 2005.

[2] Chang, Chi-Cheng., Chi-Fang Yan., and Ju-Shih Tseng., "Perceived convenience in an extended technology acceptance model: Mobile technology and English learning for college students", Australasian Journal of Educational Technology, vol. 28, no. 5,2012.

[3] Anderson, Keith J. "Internet use among college students: An exploratory study" Journal of American College Health, vol. 50, no. 1, pp.21-26, 2001.

[4] Chen, Ying-Fang, and Samuel S. Peng., "University students' Internet use and its relationships with academic performance, interpersonal relationships, psychosocial adjustment, and self-evaluation" Cyber Psychology \& Behavior, vol. 11, no. 4, pp.467-469, 2008.

[5] Kirschner, Paul A., and Aryn C. Karpinski., "Facebook® and academic performance", Computers in human behavior, vol. 26, no. 6, pp.1237-1245, 2010.

[6] Gemmill, Erin L., and Michael Peterson., "Technology use among college students: Implications for student affairs professionals", NASPA Journal, vol. 43, no. 2, pp.280-300, 2006.

[7] Crews, Fulton, Jun He, and Clyde Hodge., "Adolescent cortical development: a critical period of vulnerability for addiction", Pharmacology Biochemistry and Behavior, vol. 86, no. 2, pp.189-199, 2007.

[8] Chambers, R. Andrew, Jane R. Taylor, and Marc N. Potenza,"Developmental neurocircuitry of motivation in adolescence: a critical period of addiction vulnerability", American Journal of Psychiatry, vol. 160, no. 6, pp.1041$1052,2003$.

[9] Sawyer, Susan M., Rima A. Afifi, Linda H. Bearinger, Sarah-Jayne Blakemore, Bruce Dick, Alex C. Ezeh, and George C. Patton,"Adolescence: a foundation for future health", The Lancet, vol. 379, no. 9826, pp.1630-1640, 2012.

[10] Kuncel, Nathan R., Sarah A. Hezlett, and Deniz S. Ones,"Academic performance, career potential, creativity, and job performance: Can one construct predict them all?", Journal of Personality and Social Psychology, vol. 86, no. 1, pp.148, 2004.

[11] Brown, R. I. F, "Some contributions of the study of gambling to the study of other addictions. In WR Eadingtone \& JA Cornclius, Gambling Behavior and Problem Gambling", Reno, NV: University of Nevada Press. pp. 341-372.

[12] Griffiths, M. D., “Internet addiction: fact or fiction?”, Psychologist, vol. 12, pp.246-250.

[13] Andreassen, Cecilie Schou, Torbjørn Torsheim, Geir Scott Brunborg, and Ståle Pallesen, "Development of a Facebook addiction scale", Psychological reports, vol.110, no. 2, pp. 501-517, 2012.

[14] Karakose, Turgut, Ramazan Yirci, Harun Uygun, and Tuncay Yavuz Ozdemir, "Relationship between High School Students' Facebook Addiction and Loneliness Status", Eurasia Journal of Mathematics, Science \& Technology Education, vol. 12, no. 9, 2016.

[15] Koc, Mustafa, and Seval Gulyagci, "Facebook addiction among Turkish college students: The role of psychological health, demographic, and usage characteristics", Cyberpsychology, Behavior, and Social Networking, vol.16, no. 4, pp. 279-284, 2013.

[16] Yang, Chia-chen, and B. Bradford Brown, "Motives for using Facebook, patterns of Facebook activities, and late adolescents' social adjustment to college", Journal of Youth and Adolescence, vol. 42, no. 3, pp.403-416, 2013.

[17] Ryan, Tracii, Andrea Chester, John Reece, and Sophia Xenos, "The uses and abuses of Facebook: A review of Facebook addiction", pp.133-148, 2014.

[18] Hart, Michael, "A study on the motives of high school and undergraduate college students for using the social network site Facebook", 2010.

[19] Thompson, Sharon H., and Eric Lougheed, "Frazzled by Facebook? An exploratory study of gender differences in social network communication among undergraduate men and women", College Student Journal, vol. 46, no. 1, 2012.

[20] Wan Chik, W. Z., Yenna Salamonson, B. Everett, Lucie M. Ramjan, Nathan Attwood, Roslyn Weaver, Z. Saad, and Patricia M. Davidson, "Gender difference in academic performance of nursing students in a Malaysian university college", International Nursing Review, vol.59, no.3, pp.387-393, 2012.

[21] Dayioğlu, Meltem, and Serap Türüt-Așik, "Gender differences in academic performance in a large public university in Turkey", Higher Education, vol.53, no.2, pp. 255-277, 2007.

[22] Fortin, Nicole M., Philip Oreopoulos, and Shelley Phipps, "Leaving boys behind gender disparities in high academic achievement", Journal of Human Resources, vol.50, no. 3, pp.549-579, 2015.

[23] Yeap, Jasmine AL, T. Ramayah, Sherah Kurnia, Hasliza Abdul Halim, and Noor Hazlina Ahmad, "The assessment of Internet addiction among university students: some findings from a focus group", Tehnički vjesnik, vol.22, no. 1, pp.105-111, 2015.

[24] Richtel, Matt. "Hooked on gadgets, and paying a mental price." The New York Times 7, 2010.

[25] Wallis, Claudia, "The multitasking generation", Time Magazine, vol.167, no. 13, pp.48-55,2006.

[26] Nalliveettil, George Mathew, and Talal Hail Khaled Alenazi, "The impact of mobile phones on English language learning: Perceptions of EFL undergraduates", Journal of Language Teaching and Research, vol.7, no. 2, pp.264-272, 2016. 
[27] Espinosa, Linda M., James M. Laffey, Tiffany Whittaker, and Yanyan Sheng, "Technology in the home and the achievement of young children: Findings from the early childhood longitudinal study", Early Education and Development, vol.17, no. 3, pp.421-441, 2006.

[28] Kittinger, Robert, Christopher J. Correia, and Jessica G. Irons, "Relationship between Facebook use and problematic Internet use among college students", Cyberpsychology, Behavior, and Social Networking, vol.15, no.6, pp.324-327, 2012.

[29] Kuss, Daria J., and Mark D. Griffiths, "Online social networking and addiction-a review of the psychological literature", International Journal of Environmental Research and Public Health, vol.8, no.9, pp.3528-3552, 2011.

[30] Kubey, Robert W., Michael J. Lavin, and John R. Barrows, "Internet use and collegiate academic performance decrements: Early findings", Journal of Communication, vol.51, no.2, pp.366-382, 2001.

[31] Pasek, Josh, and Eszter Hargittai, "Facebook and academic performance: Reconciling a media sensation with data", First Monday, vol.14, no.5, 2009.

[32] Kolek, Ethan A., and Daniel Saunders, "Online disclosure: An empirical examination of undergraduate Facebook profiles", NASPA Journal, vol.45, no.1, pp.1-25, 2008. 